\title{
Editorial: Non-polysaccharide Plant Polymeric Materials
}

\author{
José Alejandro Heredia-Guerrero* and Athanassia Athanassiou* \\ Smart Materials, Nanophysics, Fondazione Istituto Italiano di Tecnologia (IIT), Genoa, Italy
}

Keywords: plant polymers, agro-waste, kerogen, sporopollenin, cork, suberin, cutin

\section{The Editorial on the Research Topic}

\section{Non-polysaccharide Plant Polymeric Materials}

This is a plastic's age, man, a plastic's age.

Julio Cortázar (Hopscotch, 1963)

\section{OPEN ACCESS}

Edited by:

Pellegrino Musto,

National Research Council, Italy

Reviewed by:

Anshuman Mangalum,

Rutgers University - Newark, USA

${ }^{*}$ Correspondence:

José Alejandro Heredia-Guerrero

jose.guerrero@iit.it;

Athanassia Athanassiou athanassia.athanassiou@iit.it

Specialty section:

This article was submitted to Polymer Chemistry,

a section of the journal

Frontiers in Materials

Received: 16 February 2016 Accepted: 07 March 2016

Published: 21 March 2016

Citation:

Heredia-Guerrero JA and

Athanassiou A (2016) Editorial: Non-polysaccharide Plant Polymeric

Materials.

Front. Mater. 3:15.

doi: 10.3389/fmats.2016.00015
Plastics are everywhere. Their unique combination of properties (lightweight, durability, wide range of mechanical properties, different degrees of hydrophobicity, processability, etc.), as well as the low cost in comparison with materials of similar characteristics, has allowed an impressive development of such macromolecules. Moreover, the ease of change of plastic's features by small chemical modification or by addition of fillers is an important advantage to be considered. However, they have a serious drawback related to their sustainability. Mainly plastics are derived from fossil resources, being most of them non-biodegradable in human scale of time, which leads to important environmental problems as, for instance, the alteration and destruction of ecosystems or adverse health effects.

As an alternative, biopolymers combine similar performances as common plastics with high rates of biodegradation in short times. Despite these facts, the lack of a specific large-scale technology for them and the relatively high costs for their isolation and process have been hindering their use. Nevertheless, the depletion of fossil resources and an increasingly green conscience, reflected on different new policies and regulations, have promoted the industrial interest on biopolymers. In this sense, plants are the most important renewable source of feedstock for monomers and macromolecules after appropriate chemical treatment. Traditionally, polysaccharides, with cellulose as the main protagonist, have been the most used substances. Nonetheless, as consequence of a growing demand of functional materials, other plant macromolecules habitually considered wastes have started to become valuable raw materials.

One characteristic example is the cutin, an amorphous, insoluble and hydrophobic polyester composed by polyhydroxylated fatty acids and, to a lesser extent, glycerol. It is the main component of plant cuticle, i.e., the external membrane that covers the epidermis of non-lignified parts of aerial plant organs, such as fruits, leaves, and green stems. The distribution of cutin in the plant cuticle and its interaction with other cuticular components present a significant interest and recently has been tracked by Confocal Raman Microscopy (Prats Mateu et al.) Cutin can be hydrolyzed into monomers in basic solutions, which can be repolymerized to form films with application in food packaging. For instance, cutin monomers and derivatives can be easily polymerized by non-catalyzed meltpolycondensation (Benítez et al.) At $150^{\circ} \mathrm{C}$, free-standing polyesters with very similar properties to cutin are obtained. Also, the reaction can be catalyzed by Lewis acidic ionic liquids, such as choline chloride. $2 \mathrm{ZnCl}_{2}$ (Gómez-Patiño et al.) In this case, viscous and mainly linear polymers with potential biomedical applications are synthesized.

Another kind of interesting plant barrier polymer is the suberin (Graça). It is a lipid polymer formed by $\alpha, \omega$-bifunctional fatty acids and glycerol. These $\alpha, \omega$-bifunctional fatty acids have multiple 
uses, for example, in the synthesis of polyurethanes and thermoset resins, in the fabrication of high-resistant fibers, or in the waterproofing of cellulose-base films. Additionally, they are promising for biomedical applications due to their cancer-preventing antimutagenic properties and their firming anti-wrinkle action in human skin (Graça). Cork is one of the main sources of suberin. This natural material can be used in the manufacture of high number of products, such as mechanical, thermal, and acoustic insulators in the form of panels, blocks, or sandwich structures for the construction industry (Gil).

Sporopollenin, the main component of the outer shells (exines) of pollen grains and plant spores, is another non-polysaccharide plant polymer. It shows a high chemical inertness. These exines can be employed as microcapsules and filled with substances of different nature, such as enzymes or drugs, and used in biomedical applications. Also, the sporopollenin exine surface can be chemically functionalized in several ways and used as solid support for peptide synthesis, catalysis, and ion-exchange chromatography (Mackenzie et al.)

Interestingly, some of these non-polysaccharide plant polymers, before being fully biodegraded, can be transformed into a useful and energetic macropolymer named kerogen, whose final composition depends on the chemical nature of the biological input (Gupta).

Conflict of Interest Statement: The authors declare that the research was conducted in the absence of any commercial or financial relationships that could be construed as a potential conflict of interest.

Copyright (c) 2016 Heredia-Guerrero and Athanassiou. This is an open-access article distributed under the terms of the Creative Commons Attribution License
Here, we have shown just few alternatives to plastics. It should be our responsibility (for us and for future generations) to continue and expand these research lines and make them suitable for large-scale production. It is time, reinterpreting the famous Argentine writer Julio Cortázar, for a new green plastic's age.

\section{AUTHOR CONTRIBUTIONS}

All authors listed have made substantial, direct, and intellectual contribution to the work and approved it for publication.

\section{ACKNOWLEDGMENTS}

We want to thank all authors and reviewers. Also, we would like to acknowledge the members of the Editorial Office of Frontiers in Materials (especially Lorena Escudero, Simon Chandler, and Anna Lukacs) for their help and promptness during all this long period.

\section{FUNDING}

JH-G is supported by a Marie Curie Intra-European Fellowship, financed by the EU's Seventh Framework Programme for Research (FP7).

(CC BY). The use, distribution or reproduction in other forums is permitted, provided the original author(s) or licensor are credited and that the original publication in this journal is cited, in accordance with accepted academic practice. No use, distribution or reproduction is permitted which does not comply with these terms. 